\title{
Alteraciones anatómicas e histoquímicas ocasionadas por la oidiosis en hojas de Hydrangea macrophylla (Hydrangeaceae)
}

\author{
Edgar Javier Rincón-Baron ${ }^{1 *}$, Claudia Grisales-Echeverri ${ }^{2}$, Viviana Lucia Cuaran ${ }^{3} \&$
}

Nadya Lorena Cardona-B. ${ }^{2}$

1. Universidad de Santander, Facultad de Ciencias de la Salud, Grupo de Investigación Agroambiente y SaludMICROBIOTA, calle 70 No 55-210, Campus Universitario Lagos del Cacique, Bucaramanga, Colombia; ed.rincon@mail.udes.edu.co, ejrbaron@gmail.com

2. Universidad de Antioquia, Instituto de Biología, Grupo de Investigación Fitopatología y Biotecnología de HongosFITOBIOL, Ciudad Universitaria, Calle 67 No 53-108, Medellín, Colombia; claus504@hotmail.com, nadya.cardona@udea.edu.co

3. Corporación Colombiana de Investigación Agropecuaria-AGROSAVIA, Grupo de Investigación Mejoramiento Genético Vegetal, Uso y Aprovechamiento de la Agrobiodiversidad (MGVA), Km. 32, vía al mar, vereda Galápagos, Rionegro, Santander, Colombia; vcuaran@agrosavia.co *Correspondencia

Recibido 21-I-2020. Corregido 14-VI-2020. Aceptado 30-VI-2020.

\begin{abstract}
Anatomical and histochemical alterations caused by powdery mildew on Hydrangea macrophylla (Hydrangeaceae) leaves. Introduction: There are few studies concerning the morpho-anatomical and histochemical alterations caused by powdery mildew in H. macrophylla leaves in the scientific literature. Objective: To describe and analyze anatomical and histochemical aspects of this pathosystem. Methods: More than 90 leaves of H. macrophylla (both healthy and infected leaves by powdery mildew) were collected in the nursery El Jardín del Eden, Rionegro, Antioquia, Colombia. To carry out the identification of the mycopathogen, sections were stained with Lactophenol Blue, and contrasted with specialized taxonomic keys. Transverse fragments $1 \mathrm{~cm}$ thick were fixed in a mixture of formalin, alcohol, and acetic acid. These were subsequently dehydrated using an ethanol series, clarified in Xylene, and finally embedded in Paraplast plus ${ }^{\circledR}$ to obtain 5 $\mu \mathrm{m}$ sections. Schiff's periodic acid reaction (PAS) was used to detect structural and reserve polysaccharides, Ruthenium Red for pectins, Ponseau S and Lacmoid for callose, ferric chloride for polyphenols, Sudan Black for lipids and Uvitex 2B-Hematoxylin for chitin. The sections were observed using a Nikon 80i eclipse ${ }^{\circledR}$ photon microscope, with Uvitex 2B-Hematoxylin-stained sections examined by epifluorescence using a UV-2A filter. For the observation and description of the samples by scanning electron microscopy, healthy and infected leaves were fixed and dehydrated in $100 \%$ methanol, critical point dried, and coated with gold. Results: $H$. macrophylla leaves are isobilateral and homobaric, with adaxial and abaxial epidermis of a single cellular layer. The palisade parenchyma consists of a layer of short cells, while the spongy parenchyma forms 6 to 7 cellular layers. All vascular bundles in the leaf blade are closed collaterals. Abundant idioblasts with raphides may be observed in the mesophyll, and starch is the main reserve carbohydrate present in the tissues. The leaves are hypostomatic and exhibit a paracytic pattern of superficial stomata which possess large substomatal cavities. The morphological data observed indicate that the mycopathogen is related to the genus Erysiphe. The epidermal cells affected by the pathogen exhibit thickened walls, granular cytoplasm, and papillae or cell wall appositions in the outer periclinal walls. With the deterioration of the epidermis, the underlying tissues are affected and become necrotic. Histochemical test indicate that infected plants thicken and reinforce their epidermal cell walls with primary wall materials; primarily cutin, pectins, and callose. When stained with Sudan Black, the presence of dark-colored agglomerates in the cytoplasm of epidermal cells may be related to plant defense mechanisms;
\end{abstract}

Rincón-Baron, E.J., Grisales-Echeverri, C., Cuaran, V.L., \& Cardona-B., N.L. (2020). Alteraciones anatómicas e histoquímicas ocasionadas por la oidiosis en hojas de Hydrangea macrophylla (Hydrangeaceae). Revista de Biología Tropical, 68(3), 959-976. 
and those observed in mesophilic cells to the disorganization of membrane systems. Polyphenols accumulate in the cytoplasm of infected epidermal cells. The fungal material present in epidermal tissues was clearly differentiated when stained with fluorochrome to detect chitin. Conclusions: Species of the genus Erysiphe are causative agents of powdery mildew in H. macrophylla. Necrosis of the epidermal cells is observed in response to the mycopathogen, possibly due to hypersensitive response.

Key words: biotrophs; histochemistry; Hydrangeaceae; plant histopathology; papillae; powdery mildew.

La producción de flores en Colombia está destinada principalmente a la exportación; el país ocupa el segundo lugar en el mercado a nivel mundial después de Holanda (Moreno \& Serna, 2006; Quirós, 2012; Instituto colombiano Agropecuario, 2018a). Así mismo, se ha consolidado como el principal proveedor de flores a Estados Unidos y el segundo de la Unión Europea (Calderón, 2014; Instituto colombiano Agropecuario, 2018a). Para la temporada de San Valentín 2019, se exportaron más de 35000 toneladas de flores para un total 600 millones de tallos (Ministerio de Comercio, Industria y Turismos, Colombia, 2019)

El número de hectáreas cultivadas con flores dentro del territorio colombiano es aproximadamente de 7532 distribuidas principalmente en los departamentos de Cundinamarca y Antioquia (Instituto colombiano Agropecuario, 2018a). Estas zonas presentan suelos fértiles y condiciones ambientales adecuadas para el desarrollo de los cultivos de flores (Ramírez, 2014). Actualmente, el sector floricultor antioqueño tiene registradas 2430 ha con producción de especies ornamentales. Las especies más cultivadas en el departamento son Hortensias (Hydrangea macrophylla (Thunb.) Ser.), Crisantemos (Chrysanthemum L.) y Áster (Aster L.) (Instituto colombiano Agropecuario 2018b). Para 2018, este mismo departamento registró más de 1703 ha cultivadas con H. macrophylla (Instituto colombiano Agropecuario 2018b; Ministerio de Agricultura y Desarrollo Rural de Colombia, Agronet, 2019). Es importante resaltar que entre enero y noviembre de 2018 fueron exportadas 19133 toneladas de $H$. macrophylla con un valor estimado de 70.65 mill USD (Agronegocios, 2019). Las flores $H$. macrophylla son un producto que se obtiene mediante un sistema de producción programado, al aire libre o bajo invernadero. Debido a sus inflorescencias grandes, coloridas y longevas, y por su abundante follaje verde, la planta es utilizada como ornamento en interiores y exteriores (Gilman, 1999). Además, se ha reportado que esta planta presenta propiedades medicinales (Seo et al., 2009; Yashaswini, Hegde \& Venugopal, 2011).

El género Hydrangea L. pertenece a la familia Hydrangeaceae (APG IV, 2016) y comprende aproximadamente 220 especies (Hufford, 2004). H. macrophylla es una planta originaria del continente asiático con alta adaptabilidad a ambientes húmedos (Codarin, Galopin, \& Chasseriaux, 2006; Halcomb \& Reed, 2010; Hempel, Hohe, \& Tränkner, 2018). Esta planta es un arbusto caducifolio que puede alcanzar hasta $1.5 \mathrm{~m}$ de altura, tiene inflorescencia tipo corimbo constituido por brácteas modificadas que subyacen a las flores. Presenta hojas opuestas de 7-15 cm de largo, pecioladas, de obovadas a elípticas o anchamente ovadas, gruesas, de ápice puntiagudo y margen aserrado (Simpson, 2010). La especie H. macrophylla es ampliamente cultivada por su valor ornamental, de la cual se han obtenido diferentes variedades comerciales (Cerbah et al., 2001; Dirr, 2004; Arafa, Nower, Helme, \& Adb-Elaty, 2017). Se han registrado cuatro subespecies de H. macrophylla, siendo $H$. macrophylla ssp. macrophylla y H. macrophylla ssp. serrata las más exitosas desde el punto de vista comercial (Windham et al., 2011; Reed \& Rinehart 2007).

El cultivo de H. macrophylla es afectado por patógenos que incluyen insectos (trips, pulgones), crustáceos (cochinillas) y moluscos (babosas, caracoles; Fontseré \& Pahí, 1984). También se han reportado afecciones 
ocasionadas por nemátodos (French, John, \& Williams, 1971; Basterrechea, 2005), virus (Tang, Harper, Wei, \& Clover, 2010; Dória, Nozaki, Pavan, Yuki, \& Sakate, 2011). Hongos (Hagan, Olive, Stephenson, \& Rivas-Davila, 2004; Freire \& Mosca, 2009; Windham et al., 2011; Mmbaga, Kim, Mackasmiel, \& Li, 2012). Entre los hongos que ocasionan lesiones foliares en H. macropylla se encuentran Cercospora hidrangeae Ellis \& Everh (Hagan et al., 2004), Rhizoctonia solani Kühn (Freire \& Mosca, 2009), Erysiphe polygoni DC. (Windham et al., 2011), Alternaria alternata Fr., Colletotrichum gloeosporioides Penz, Phoma exigua Desm, Myrothecium roridum Tode (Mmbaga et al., 2012). La principal enfermedad foliar ocasionada por micopatógenos en esta planta, se conoce comúnmente como Oidiosis o ceniza (Li et al., 2018; Qiu, Braun, Li, \& Li, 2019). En H. macrophylla se ha reportado que esta enfermedad puede ser ocasionada por micopatógenos del orden Erisiphales, y las especies que se reportan como agentes causantes de la Oidiosis son: Erysiphe polygoni DC., Erysiphe hydrangeae (Z.X. Chen \& R. X. Gao) U. Braun \& S. Takam., Erysiphe schizophragmatis (Tanda \& Y. Nomura) U. Braun \& S. Takam., Erysiphe yanshanensis T.Z. Liu \& U. Braun, Golovinomyces orontii (Castagne) V.P. Heluta, Erisyphe poeltii U. Braun, Pseudoidium hortensiae (Jørst.) U. Braun \& R.T.A. Cook y Oidium hortensiae Jørst (Li et al., 2009a, 2009b; Schmidt \& Scholler, 2011; Windham et al., 2011; Braun \& Cook, 2012; Park, Cho, Park, Lee \& Shin, 2012; Li et al., 2018; Qiu et al., 2019).

La sintomatología causada por estos micopatógenos es muy similar y se caracteriza por formar parches o manchas pulverulentas blancas a grises sobre la cara abaxial o adaxial de la lámina foliar (Kuhn et al., 2016; Li et al., 2018). Estos micopatógenos son parásitos biotrófos obligados que se desarrollan solo en las células epidérmicas y penetran a través de la cutícula por hifas especializadas llamadas apresorios. A partir de los apresorios se forman los haustorios, que le permiten al micopatógeno la absorción de agua y nutrientes (Li et al., 2009a, 2009b; Kuhn et al., 2016; Li et al., 2018).
Al utilizar los nutrientes del hospedero ocasiona un detrimento en la tasa fotosintética y aumento en tasa de respiración y transpiración, lo que implica menor eficiencia en el desarrollo de la planta que repercute negativamente en el vigor y afecta directamente la calidad y el valor comercial de las flores y por consiguiente la competitividad en los mercados (Agrios, 2005; Sinclair \& Lyon, 2005; Windham et al., 2011; Li et al., 2018).

En general, la mayoría de los estudios sobre micopatógenos que originan la Oidiosis en $H$. macrophylla, se han enfocado en determinar cuáles son variedades resistentes al efecto del micopatógeno y evaluar estrategias de control fitosanitario (Windham et al., 2011; Li et al., 2009a, 2009b). Por estas razones, se propuso en este trabajo realizar una descripción detallada de las alteraciones anatómicas, histológicas y citohistoquímicas ocasionadas por la Oidiosis en hojas de H. macrophylla. Referente a aspectos relevantes como la producción de polisacáridos, lípidos, pectinas, polifenoles y lignina. También posibles respuestas químicas al ataque del micopatógeno. La información obtenida se puede relacionar con la alteración de los procesos metabólicos del hospedero característicos de este pato-sistema.

\section{MATERIALES Y MÉTODOS}

Durante la época de invierno se recolectaron hojas maduras sanas de H. macrophylla e infectadas con Oidiosis o ceniza entre abril y mayo 2015. El criterio para seleccionar las hojas infectadas se hizo sensu Li et al., (2018). El material vegetal se recolecto en el vivero El Jardín del Edén en la vereda Sajonia, Municipio de Rionegro, Antioquia a $\left(06^{\circ} 09^{\prime} 47^{\prime \prime} \mathrm{N}\right.$ \& 7527’30" W) y 2316 m.s.n.m. Los especímenes de $H$. macrophylla ssp. macrophylla fueron depositados en el herbario de la Universidad de Antioquia (HUA) con la referencia de recolección Rincón 023. Para la identificación del patógeno a nivel de género, se realizaron secciones a mano alzada de las hojas que presentaban síntomas de Oidiosis, tanto en la cara adaxial como abaxial de la lámina foliar 
y estas fueron teñidas con azul de Lactofenol y se observó con contraste diferencial de interferencia (CDI). Se consultaron claves taxonómicas especializadas (Schmidt \& Scholler, 2011; Braun \& Cook, 2012).

Para analizar las características anatómicas e histoquímicas se seccionaron 30 hojas sanas y 30 infectadas, de estas se obtuvieron fragmentos transversales de $2 \mathrm{~cm}$. Estos fragmentos fueron fijados en una mezcla de formol, etanol y ácido acético (FAA) por $24 \mathrm{~h}$ a $6{ }^{\circ} \mathrm{C}$. Después de la fijación se mantuvieron en solución de alcohol-glicerol por $48 \mathrm{hr}$ a $6{ }^{\circ} \mathrm{C}$, para luego deshidratarlas en una serie gradual de etanol y dos pasos de aclaramiento en Xilol. Los fragmentos se incluyeron a Paraplast plus ${ }^{\circledR}$ durante $12 \mathrm{hr}$ a $55^{\circ} \mathrm{C}$ (Ruzin, 1999). El material embebido fue seccionado a $5 \mu \mathrm{m}$ de grosor en un micrótomo rotatorio LEICA RM 2125®.

Las secciones obtenidas se tiñeron con Safranina-azul de Alcian para realizar des $\neg$ cripciones de tejidos con paredes primarias y secundarias, además de resaltar de cutina y de forma no especifica, polifenoles (Ruzin, 1999; Demarco, 2017), rojo de Rutenio para determinar la presencia de pectinas (Sandoval, 2005; Soukup, 2014). Se utilizó Lacmoid y Ponceau S para calosa (Ramming, Hinrichs, \& Richardson, 1973; Ulryghová, Petrü, \& Pazourková, 1976; Soukup, 2014). Así mismo, Cloruro férrico para polifenoles totales (Peterson, Peterson, \& Melville, 2008; Demarco, 2017) y negro de Sudán para lípidos estructurales (Demarco, 2017). Se empleó Uvitex-Hematoxilina para la detección de quitina y núcleos celulares (Sørensen, Justesen, \& Hovmøller, 2012; Dugyala, Borowicz, \& Acevedo, 2015), para detectar lignina se empleó Floroglucinol ácido (Soukup, 2014; Demarco, 2017) y para carbohidratos la tinción de PAS (Ruzin, 1999; Demarco, 2017).

Las observaciones se realizaron mediante un microscopio fotónico Nikon 80i eclipse ${ }^{\circledR}$ equipo con el sistema de contraste diferencial de interferencia (CDI). Las fotografías se obtuvieron con cámara digital Nikon (DSfi 1) utilizando el programa NIS- Elements (BR 4.30.02.). Las secciones tratadas con
Uvitex-Hematoxilina se examinaron mediante microscopía de epifluorescencia utilizando filtro UV- 2A (filtro de excitación 330-380 $\mathrm{nm}$ y filtro barrera $420 \mathrm{~nm}$ ) (Ruzin, 1999). El término papilas (o aposiciones de la pared celular) se empleó sensu Underwood (2007) y Voigt (2014).

Para llevar a cabo las descripciones morfológicas con microscopía electrónica de barrido (MEB), fragmentos de las hojas sanas e infectadas se fijaron y deshidrataron en metanol al $100 \%$ por 48 horas, efectuando dos cambios en este solvente (Talbot \& White, 2013). Posteriormente, se desecaron a punto crítico con un desecador SAMDRI®-795. Las muestras se montaron sobre cinta conductiva de carbono de doble cara y se recubrieron con oro en una ionizadora DENTON VACUUM DESK IV durante $8 \mathrm{~min}$. Las observaciones y registro fotográfico se realizaron en un microscopio electrónico de barrido JEOL JSM-6490LV.

\section{RESULTADOS}

H. macrophylla ssp. macrophylla es un arbusto de hojas simples opuestas decusadas de color verde intenso, presentan inflorescencias terminales tipo corimbo (Fig. 1A). Las plantas observadas en el sitio de recolecta pueden presentar inflorescencias de diferentes colores, que depende principalmente del $\mathrm{pH}$ de los suelos y la variedad de las plantas. Los colores de las inflorescencias van desde el azul intenso al rojo, e incluso variedades de color blanco (Fig. 1A). Las plantas afectadas por la Oidiosis, por lo general presentan un micelio externo fino que forma manchas pulverulentas de color blanco o grisáceos, que se desarrollan tanto en la cara abaxial como en la adaxial de la lámina foliar. Con el progreso de la infección, estas masas de micelio cubren todo el limbo foliar y se puede apreciar lesiones de color oscuro (Fig. 1B). Los síntomas también pueden ser visibles en las brácteas florales de color blanco y se aprecian como manchas de color marrón-rojizo (Fig. 1C). Las células epidérmicas adaxiales presentan una cutícula que forma estrías epicuticulares que son más conspicuas en algunas 


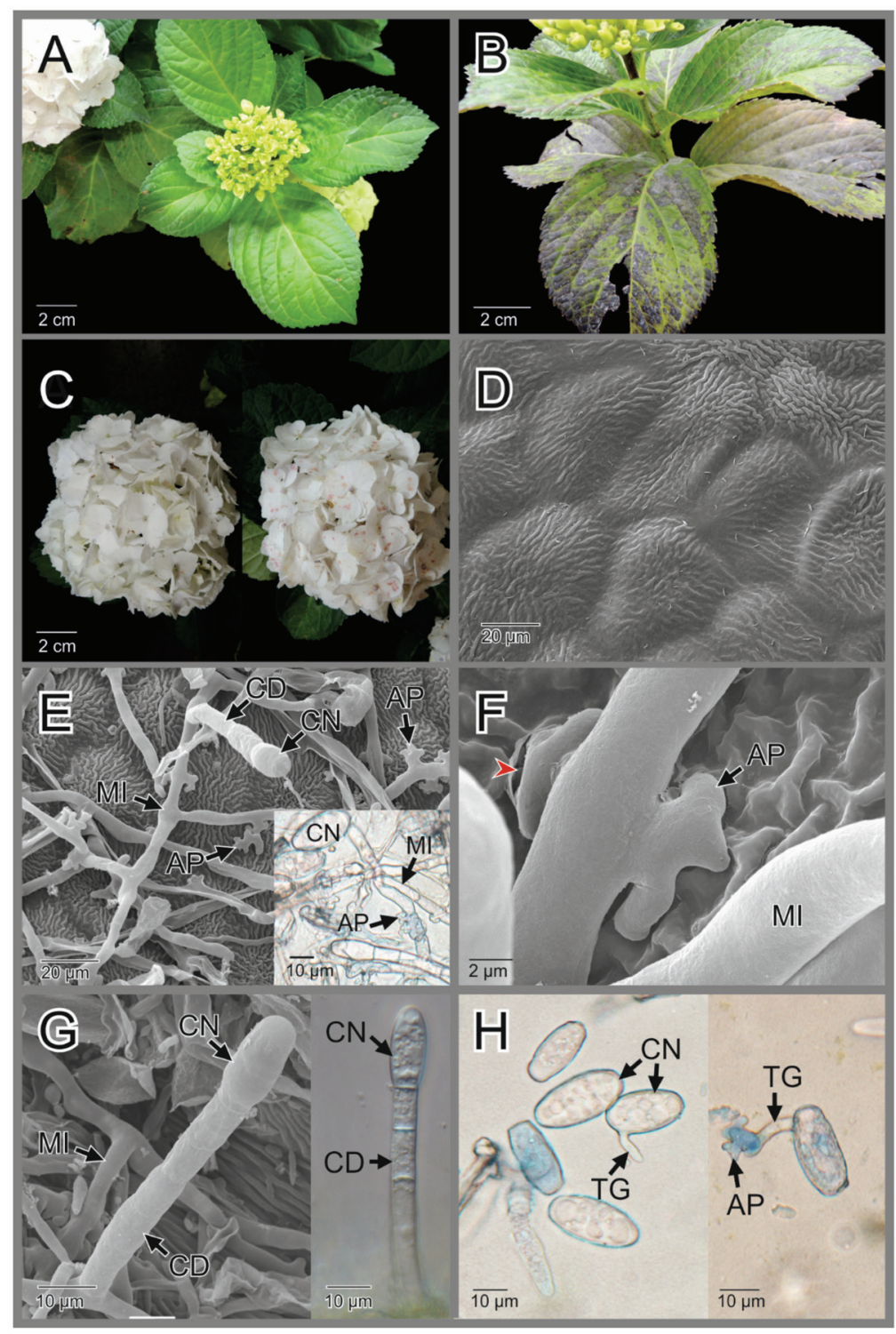

Fig. 1. AP: apresorio; CD: conidióforos; CN: conidias; MI: micelio; TG: tubo de germinación. Hydrangea macrophylla. Plantas sanas e infectadas por la Oidiosis o ceniza y características del hongo causante de la enfermedad. A. Planta sana. B. Planta infectada. C. Corimbos florales sanos (izquierda) e infectados (derecha). D. Superficie de la epidermis adaxial de las hojas sanas, se observan estrías cuticulares (Microscopía electrónica de barrido-MEB). E-G. Características morfológicas del micelio externo mostrando apresorios, conidiforos y conidias. El detalle en $\mathbf{E}$ corresponde a una sección a mano alzada y teñida con azul de Lactofenol. En F , la cabeza de flecha roja indica el deterioro de la cutícula (Microscopía electrónica de barrido-MEB). En $\mathbf{H}$ detalles de las conidias y tubos de germinación teñidas con azul de lactofenol.

Fig. 1. AP: appressorium; CD: conidiophores; CN: conidia; MI: mycelium; TG: germination tube. Hydrangea macrophylla. Healthy and infected plants with powdery mildew and characteristics of the disease-causing fungus. A. Healthy plant. B. Infected plant. C. Healthy (left) and infected (right) floral corymbs. D. Surface of the adaxial epidermis in healthy leaves, showing cuticular striations (scanning electron microscopy (SEM)). E-G. Morphological characteristics of the mycelium, appressorium, conidiophores, and conidia. The detail view in $\mathbf{E}$ depicts a freehand section stained with Lactophenol Blue. In $\mathbf{F}$, the red arrowhead indicates the damage to the cuticle (scanning electron microscopy (SEM)). H. Provides a detailed view of the conidia and germination tubes, stained with Lactophenol Blue. 
células que en otras (Fig. 1D). Tanto en la superficie adaxial como abaxial de las hojas y brácteas florales $H$. macrophylla infectadas con Oidiosis se observó la presencia de un micelio externo hialino septado, ramificado y con numerosos apresorios multilobulados (Fig. 1E). Los apresorios se aprecian fuertemente adheridos a la cutícula, la cual se aprecia desgastada y con deterioro en los puntos de contacto con esta estructura fúngica (Fig. 1F). Los conidióforos son ligeramente curvados y por lo general de 2-3 células y presentan una conidia terminal elipsoide o algunas veces ovoide con numerosos gránulos refringentes en el citoplasma (Fig. 1G). Por lo general, forman un tubo de germinación corto por conidia que termina en un apresorio multilobulado (Fig. 1H). No se apreciaron estructuras de reproducción sexual de la Oidiosis en las muestras de hojas procesadas y analizadas en esta investigación".

\section{Observaciones anatómicas de las hojas} sanas: la epidermis de las hojas es glabra, monoestratificada y está constituida por células de contorno redondeado a rectangular a ambos lados de la lámina foliar, siendo de mayor tamaño las del lado adaxial (Fig. 2A). Tanto la epidermis adaxial como la abaxial presentan una cutícula delgada y poco perceptible incluso a los máximos aumentos en las que fue observada. Las hojas de H. macrophylla son homobáricas y presentan mesófilo dorsivental. En el lado adaxial del mesófilo se encuentra el parénquima de empalizada que está constituido por un estrato de células cortas con abundantes cloroplastos (Fig. 2A). Luego se encuentra el parénquima esponjoso que por lo general forma entre 6-7 estratos de células que delimitan grandes espacios aeríferos, pero convergen alrededor de haces vasculares secundarios o terciarios (Fig. 2A).

Las células del parénquima aerífero son cortas ramificadas y también presentan numerosos cloroplastos. Entre las células del parénquima esponjoso, se observó la presencia de idioblastos con rafidios de oxalato de calcio que se aprecian refringentes al observarlos con luz polarizada (Fig. 2B). El haz vascular de primer orden es biconvexo, forma una amplia curvatura sobre la superficie abaxial y una angosta en el lado adaxial. La epidermis en ambos lados de esta nervadura es uniestratificada y constituida por células de contorno cuadro a rectangular y cubiertas por una cutícula delgada (Fig. 2C).

En los tejidos subepidérmicos de la cara abaxial de la nervadura primaria, se aprecian entre 3-5 capas de colénquima angular en tanto que en el lado adaxial se observaron entre 7-10 capas de este mismo tejido (Fig. 2C). Los haces vasculares de la nervadura principal son colaterales cerrados que forma un único arco dispuesto hacia lado adaxial en forma cóncavaconvexa, estos haces están inmersos en parénquima fundamental (Fig. 2C). El floema forma varias filas de células hacia la cara abaxial de la nervadura en tanto que el xilema se aprecia en disposición radial formando entre 25 a 30 brazos (Fig. 2C). El haz vascular de segundo orden es colateral cerrado y está soportado por columnas de parénquima y colénquima. Este haz está formado por entre cuatro a cinco brazos de xilema y varias capas de floema dirigidas hacia el lado adaxial de la nervadura (Fig. 2D). El almidón fue la principal sustancia de reserva detectada en los tejidos foliares (Fig. 2E). Las hojas de H. macrophylla son hipostomáticas y con patrón estomático paracítico, con estomas superficiales que permiten el paso a la cavidad subestomática (Fig. 2F).

Observaciones anatómicas de las hojas infectadas: sobre la pared periclinal externa de las células epidérmicas se observan estructuras fúngicas características del micopatógeno, tales como micelio y conidias (Fig. 2G). Las paredes de las células epidérmicas se aprecian con engrosamientos cuticulares, de color rojo, por la reacción a la Safranina y el citoplasma se aprecia granular (Fig. 2G). En etapas tempranas de la infección, los tejidos subepidérmicos no se ven afectados y estos se aprecian funcionales, en buen estado y con abundantes cloroplastos. En la cara interna de las paredes periclinales externas de algunas células epidérmicas tanto del lado adaxial como del abaxial, se aprecia la 


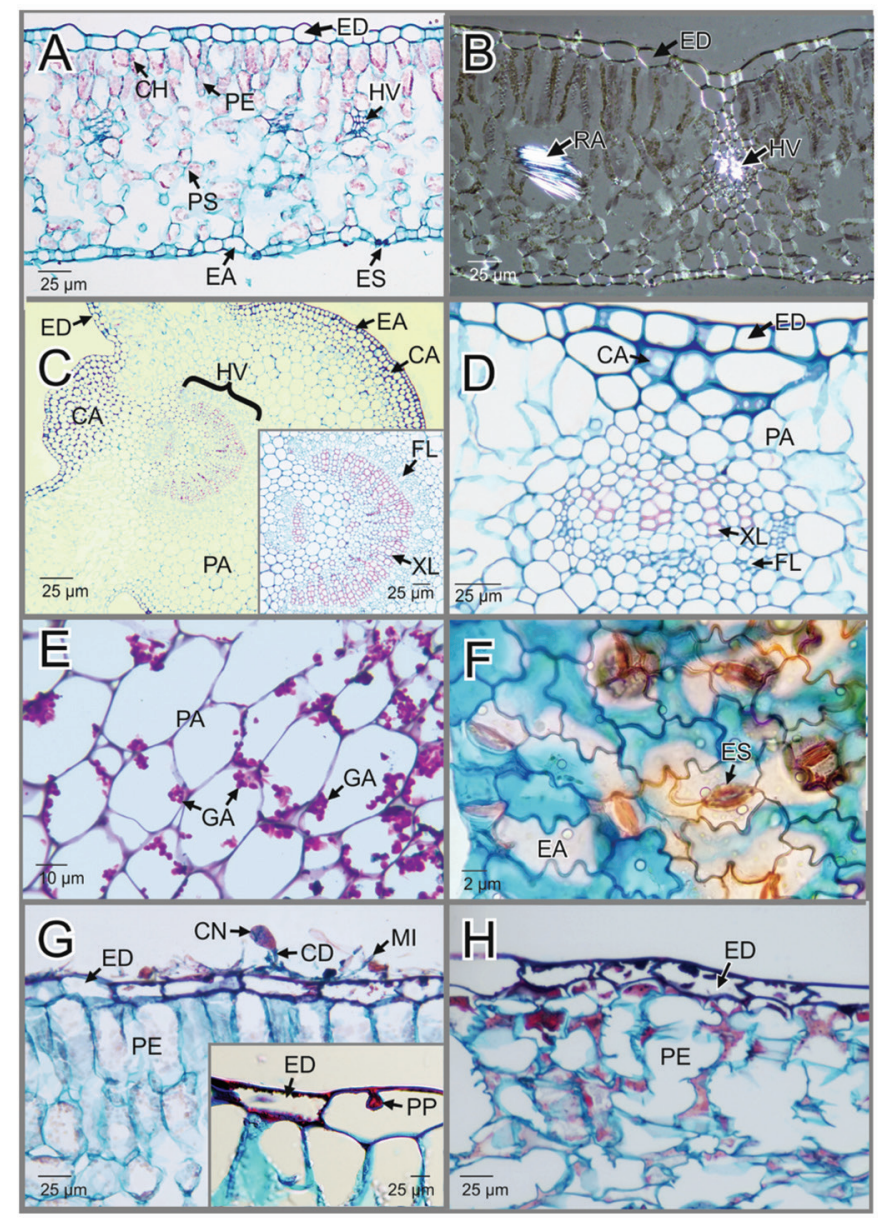

Fig. 2. CA: colénquima angular; $\mathrm{CD}$ : conidióforos; $\mathrm{CH}$ : cloroplastos; $\mathrm{CN}$ : conidias; EA: epidermis abaxial; ED: epidermis adaxial; ES: estoma; FL: floema; GA: gránulos de almidón; HV: haz vascular; MI: micelio; PA: parénquima fundamental o de relleno; PE: parénquima de empalizada; PP: papilas; PS: parénquima esponjoso; RA: rafidios; XL: xilema. Hydrangea macrophylla. Característica morfo-anatómicas de las hojas sanas e infectadas por la Oidiosis o ceniza. A-B. Secciones transversales de las hojas sanas, teñidas con Safranina-azul de Alcian. En campo claro y con luz polarizada, respectivamente. C-D. Secciones trasversales de las nervaduras de primer y segundo orden de las hojas sanas, respectivamente (Safraninaazul de Alcian). En $\mathbf{C}$ se aprecia en el recuadro, un detalle del haz vascular de primer orden. E. Detalle del parénquima de la nervadura (reacción del ácido peryódico de Schiff). F. Detalle de la epidermis abaxial (Safranina-azul de Alcian). G-H. Secciones transversales de las hojas infectadas (Safranina-azul de Alcian). G. Infección temprana. Se aprecian, el micelio externo, conidias y conidioforos sobre la pared periclinal. En el recuadro, se observa un detalle de la epidermis adaxial. $\mathbf{H}$. Sección transversal de la hoja mostrando un detalle del avance de la infección.

Fig. 2. CA: angular collenchyma; CD: conidiophores; $\mathrm{CH}$ : chloroplasts; $\mathrm{CN}$ : conidia; EA: abaxial epidermis; ED: adaxial epidermis; EN: stoma; FL: phloem; GA: starch granules; HV: vascular bundle; MI: mycelium; PA: fundamental parenchyma; PE: palisade parenchyma; PP: papillae; PS: spongy parenchyma; RA: raphides; XL: xylem. Hydrangea macrophylla. Morpho-anatomical characteristics of healthy leaves and leaves infected by powdery mildew. A-B. Transverse sections of the healthy leaves, stained with Alcian Blue-Safranine; under a clear field and polarized light respectively. C-D. Transverse sections of the first and second-order vascular bundles of the healthy leaves respectively (Alcian Blue-Safranine). In $\mathbf{C}$, one can observe a detail view of the vascular bundle in the box. E. Detail of the parenchyma of the vascular bundle (Schiff's periodic acid reaction). F. Detail of the abaxial epidermis. (Alcian Blue-Safranine) can be observed. G-H. Transverse sections of infected leaves (Alcian Blue-Safranine). G. Early infection. The external mycelium, conidia, and conidiophores on the outer periclinal wall of the epidermis. In the box, a detail of the adaxial epidermis is observed. H. Cross section of the leaf, showing a detail of the progress of the infection. 


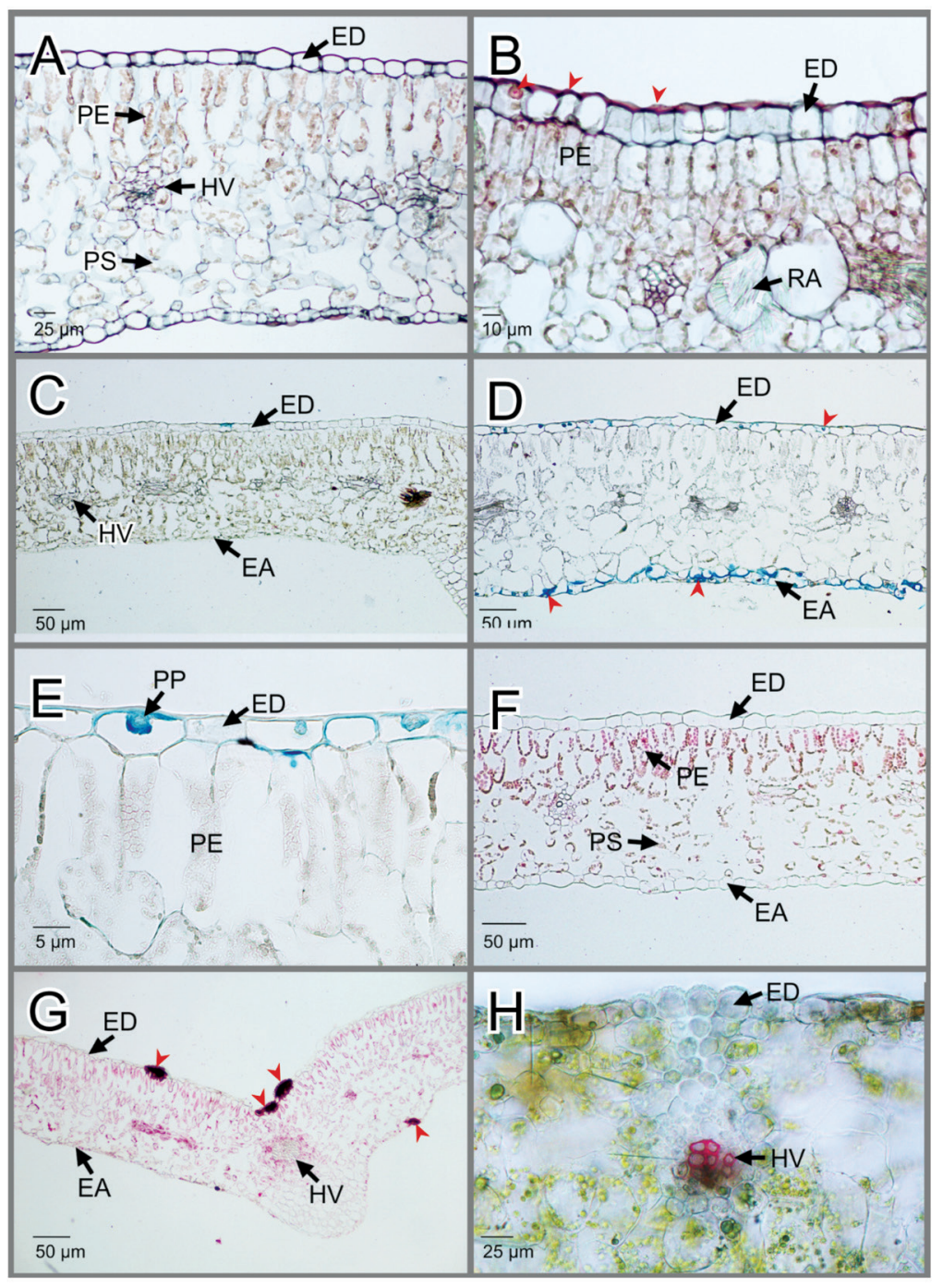

Fig. 3. EA: epidermis abaxial; ED: epidermis adaxial; HV: haces vasculares; PE: parénquima de empalizada; PP: papilas; PS: parénquima esponjoso; RA: rafidios. Hydrangea macrophylla. Pruebas histoquímicas aplicadas a las secciones de hojas sanas e infectadas por la Oidiosis o ceniza. A-B. Secciones transversales de hojas sanas e infectadas teñidas con rojo de Rutenio, respectivamente. En B Se aprecian engrosamientos de pectinas en las células epidérmicas y papilas presentes en las hojas infectadas (cabezas de flecha roja). C-D. Secciones transversales de hojas sanas e infectadas teñidas con Lacmoid, respectivamente. Se indica la calosa (cabezas de flecha roja). E. Detalle de la epidermis adaxial teñida con Lacmoid mostrando las papilas. F-G. Secciones transversales de hojas sanas e infectadas teñidas con Pounceau S, respectivamente. Se indica la calosa (cabezas de flecha roja). H. Sección trasversal de hoja infectada teñida con Floroglucinol ácido. El color fucsia en el haz vascular indica la presencia de lignina.

Fig. 3. EA: abaxial epidermis; ED: adaxial epidermis; HV: vascular bundles; PE: palisade parenchyma; PP: papillae; PS: spongy parenchyma; RA: raphides. Hydrangea macrophylla. Histochemical tests applied to sections of healthy leaves and leaves infected by powdery mildew. A-B. Transverse sections of healthy leaves and infected leaves respectively, stained with Ruthenium Red. In $\mathbf{B}$ epidermal cells and papillae of infected leaves (red arrowheads) thickened by pectins. C-D. Transverse sections of healthy and infected leaves respectively, stained with Lacmoid. Callose is indicated (red arrowheads). E. Detail of the adaxial epidermis stained with Lacmoid, showing the papillae. F-G. Transverse sections of, respectively, healthy and infected leaves, stained with Ponceau S. Callose is indicated (red arrowheads). H. Transverse section of infected leaf stained with Phloroglucinol acid. The fuchsia color in the vascular bundle indicates the presence of lignin. 
formación de engrosamientos en forma papilas (Fig. 2G). Posteriormente, con el avance de la infección, se observa necrosis tanto de las células epidérmicas como de los tejidos fotosintéticos yuxtapuestos (Fig. 2H). Estos tejidos se aprecian desorganizados, colapsados y con inclusiones citoplasmáticas que reaccionan con la safranina, sugiriendo la presencia de polifenoles y no se aprecian cloroplastos.

Aspectos histoquímicos de hojas sanas e infectadas: $\mathrm{Al}$ analizar algunas características histoquímicas en las hojas sanas, se aprecia que las células epidérmicas tienen paredes primarias delgadas que dan positivo al rojo de Rutenio, indicando la presencia de pectinas (Fig. 3A). En contraste y en respuesta a esta misma tinción, en las paredes periclinales de las células epidérmicas de las hojas infectadas, se observan engrosamientos conspicuos que indican la presencia y mayor acumulación de pectinas (Fig. 3B). Las papilas también reaccionaron de manera positiva con esta tinción. Se observó reacción cruzada del rojo de Rutenio con los cloroplastos de los tejidos tanto de hojas sanas como infectadas (Fig. 3A, 4B). Las células epidérmicas de las hojas sanas no presentan ninguna reacción con el Lacmoid (Fig. 3C); contrario a la reacción en color azul conspicua que se aprecia en algunas zonas de las células epidérmicas de las hojas infectadas, indicando la presencia de calosa (Fig. 3D). Esta reacción, también es evidente en las estructuras papilares que se aprecian en estas mismas células en la cara interna de las paredes periclinales externas (Fig. 3E). Las células epidérmicas de las hojas sanas no reaccionan con la tinción de Punceau S, excepto los cloroplastos (Fig. 3F), en tanto que las células epidérmicas infectadas reaccionan formando aglomerados de color rojo intenso que indica la presencia de calosa. Así mismo, se aprecia reacción cruzada de esta tinción con los cloroplastos de las hojas analizadas (Fig. 3G). Las células epidérmicas tanto de los tejidos sanos como infectados no reaccionan con el Floroglucinol ácido, en tanto que el xilema de los haces vasculares se tiñe de color fucsia, indicando la presencia de lignina (Fig. 3H).

Los tejidos de las hojas sanas reaccionan de manera negativa con las tinciones de Cloruro férrico y negro de Sudan, respectivamente (Fig. 4A, 4C). Por el contrario, en las hojas infectadas con la Oidiosis, se aprecian agregados citoplasmáticos de color negro en las células epidérmicas y tejidos fotosintéticos con esta última tinción, sugiriendo la presencia de materiales lipídicos (Fig. 4B). Solo en las células epidérmicas de las hojas infectadas, se observaron agregados citoplasmaticos de color negro al aplicar Cloruro férrico (Fig. 4D). La Tinción con Uvitex 2B-Hematoxilina muestra reacción cruzada con las paredes celulares de los tejidos foliares sanos de H. macrophylla en color azul oscuro (Fig. 4E), pero presenta reacción especifica de color azul claro brillante con el material fúngico quitinoso (Fig. 4F). Las pruebas histoquímicas efectuadas y los compuestos determinados se resumen en la Tabla 1.

\section{DISCUSION}

En plantas de H. macrophylla se ha reportado que la Oidiosis es ocasionada principalmente por micopatógenos pertenecientes a los géneros Erysiphe, Golovinomyces, Pseudoidium (Li et al., 2009a, 2009b; Braun \& Cook, 2012) y en algunos casos por el género Oidium (Park et al., 2012). Las observaciones morfológicas registras en esta investigación en relación con las conidias, tubos de germinación, conidiforos, apresorios y en comparación con la literatura científica analizada, permite indicar que el agente fúngico implicado en la Oidiosis en las muestras analizadas de H. macrophylla, se relaciona con el género Erysiphe (Li et al., 2009a, 2009b; Schmidt \& Scholler, 2011; Ale-Agha et al., 2013). No obstante, en esta investigación no se encontraron estructuras de reproducción sexual, que son importantes para la determinación taxonómica de las especies dentro del género (Braun \& Cook, 2012). Por lo cual, se recomienda realizar análisis filogenéticos moleculares y morfológicos que incluyan aspectos de la reproducción sexual, que 


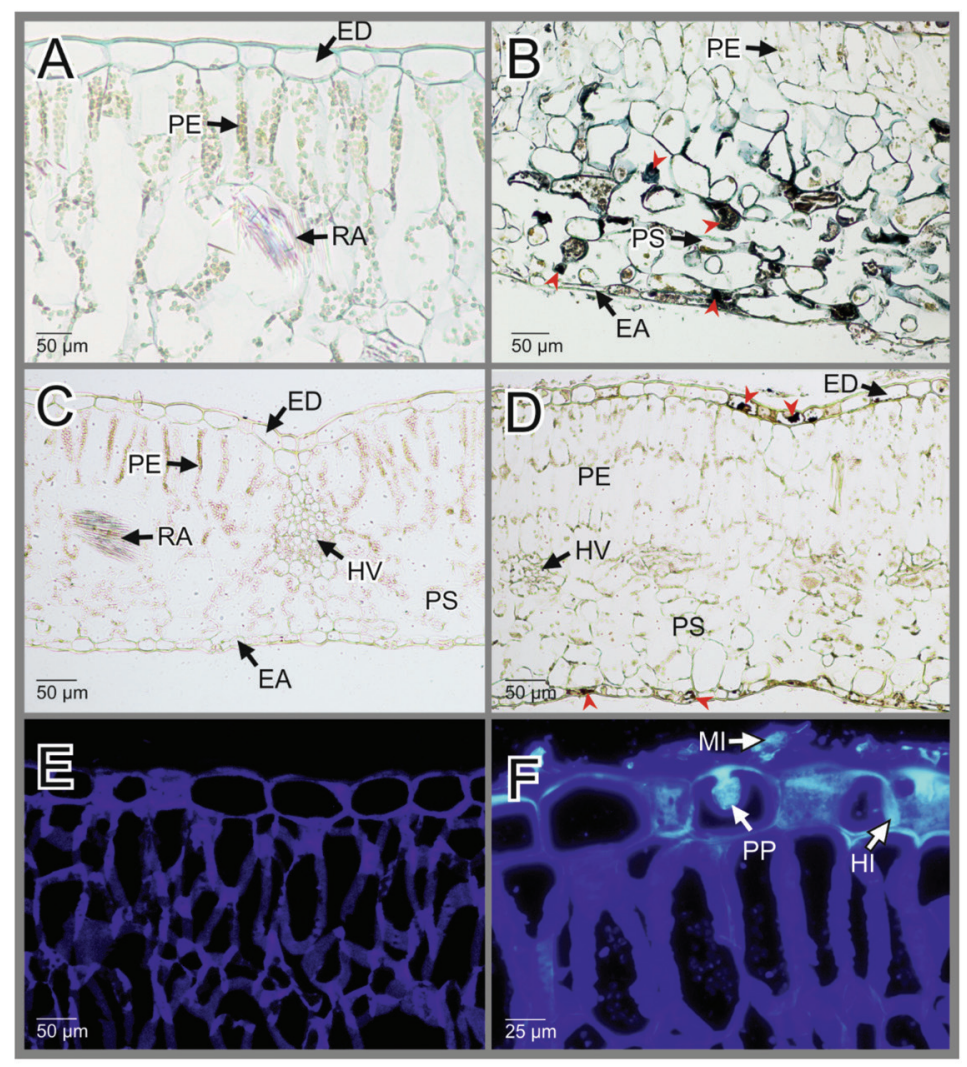

Fig. 4. EA: epidermis abaxial; ED: epidermis adaxial; HV: haces vasculares; MI: micelio; PE: parénquima de empalizada; PP: papilas; PS: parénquima esponjoso; RA: rafidios. Hydrangea macrophylla. Pruebas histoquímicas aplicadas a las secciones de hojas sanas e infectadas por la Oidiosis o ceniza. A-B. Secciones transversales de hojas sanas e infectadas respectivamente teñidas con negro de Sudan. En B, Los agregados de color negro indicarían la presencia de lípidos (cabezas de flecha roja). C-D. Secciones transversales de hojas sanas e infectadas respectivamente, teñidas con Cloruro férrico. En D, los agregados negros, indicarían la presencia de presencia de polifenoles (cabezas de flecha roja). E-F. Secciones transversales de hojas sanas e infectadas teñidas respectivamente con Uvitex 2B-Hematoxilina (microscopía de fluorescencia).

Fig. 4. EA: abaxial epidermis; ED: adaxial epidermis; HV: vascular bundles; MI: mycelium; PE: palisade parenchyma; PP: papillae; PS: spongy parenchyma; RA: raphides. Hydrangea macrophylla. Histochemical tests applied to sections of healthy leaves and leaves infected by powdery mildew. A-B. Transverse sections of healthy and infected leaves respectively, stained with Sudan Black. In B, black aggregates would indicate the presence of lipids (red arrowheads). C-D. Transverse sections of healthy and infected leaves respectively, stained with ferric chloride. In $\mathbf{D}$, the black aggregates would indicate the presence of polyphenols (red arrowheads). E-F. Transverse sections of healthy and infected leaves respectively, stained with Uvitex 2B- Hematoxylin (fluorescence microscopy).

permitan determinar en un esquema natural, la circunscripción exacta de la especie causante de la Oidiosis en las plantaciones de $H$. macropylla del nororiente antioqueño. El gran número de apresorios observados en el patosistema $H$. macropylla-Oidiosis que afectan a las células epidérmicas, estaría relacionado con las repuestas del patógeno ante los mecanismos de resistencia presentes en la planta, tales como el depósito de calosa, engrosamientos de pectina y acumulación de polifenoles; tal y como lo han indicado otros autores para Erysiphales ( $\mathrm{Li}$ et al., 2009a, 2009b).

Así mismos, la estrecha relación entre los apresorios y el deterioro de la cutícula observados en este pato-sistema, es congruente 
TABLA 1

Pruebas histoquímicas aplicadas a hojas sanas e infectadas de Hydrangea macrophylla con Oidiosis

TABLE 1

Histochemical tests applied to healthy and infected leaves of Hydrangea macrophylla with powdery milde

\begin{tabular}{|c|c|c|c|c|}
\hline \multirow{2}{*}{ Compuesto } & \multirow{2}{*}{ Reactivo } & \multirow{2}{*}{$\begin{array}{l}\text { Reacción } \\
\text { de color }\end{array}$} & \multicolumn{2}{|c|}{ Sitio en el que se probó el compuesto } \\
\hline & & & Muestras sanas & Muestras infectadas \\
\hline Calosa & Ponceau & Rojo & Cloroplastos $(+)$ & $\begin{array}{l}\text { Papilas }(+) \text {, cloroplastos }(+), \\
\text { paredes anticlinales y periclinales } \\
\text { de células epidérmicas }(+)\end{array}$ \\
\hline Calosa & Lacmoid & Azul claro & Todos los tejidos (-) & $\begin{array}{l}\text { Papilas }(+) \text {, paredes anticlinales } \\
\text { y periclinales de células } \\
\text { epidérmicas }(+)\end{array}$ \\
\hline Lípidos & Negro de Sudan & Café a negro & Reacción con cloroplastos $(+)$ & $\begin{array}{l}\text { Células epidérmicas y } \\
\text { parenquimatosas }(+)\end{array}$ \\
\hline Pectinas & Rojo de Rutenio & Rojo & $\begin{array}{l}\text { Reacción leve con células de } \\
\text { paredes primarias y cloroplastos }(+)\end{array}$ & $\begin{array}{l}\text { Papilas }(+) \text {, paredes anticlinales } \\
\text { y periclinales de células } \\
\text { epidérmicas }(+) \text { y cloroplastos }(+)\end{array}$ \\
\hline Polifenoles & Cloruro férrico & Café a negro & Todos los tejidos (-) & Células epidérmicas $(+)$ \\
\hline $\begin{array}{l}\text { Polisacáridos de } \\
\text { reserva, almidón }\end{array}$ & PAS & Fucsia & $\begin{array}{l}\text { Células parenquimatosas }(+), \text { los } \\
\text { demás tejidos }(-)\end{array}$ & $\begin{array}{l}\text { Células parenquimatosas }(+), \text { los } \\
\text { demás tejidos }(-)\end{array}$ \\
\hline Quitina & $\begin{array}{l}\text { Uvitex- Hematoxilina* } \\
\text { (filtro UV) }\end{array}$ & $\begin{array}{l}\text { Azul claro } \\
\text { brillante }\end{array}$ & $\begin{array}{l}\text { Paredes celulares vegetales (-) } \\
\text { reacción cruzada de las paredes } \\
\text { primarias en azul oscuro. }\end{array}$ & Paredes fúngicas y papilas $(+)$ \\
\hline Lignina & Floroglucinol ácido, & Rojo & $\begin{array}{l}\text { Paredes de células epidérmicas (-) } \\
\text { En el xilema }(+)\end{array}$ & $\begin{array}{l}\text { Paredes de células epidérmicas (-) } \\
\text { En el xilema }(+)\end{array}$ \\
\hline
\end{tabular}

con los mecanismos de presión y degradación enzimática ejercidos por el apresorio, y que han sido ampliamente documentados para diferentes interacciones entre planta-micopatógeno (Dean, 1997; Zabka et al., 2007; Ryder \& Talbot, 2015). Las características anatómicas de hojas de H. macrophylla observadas en esta investigación son congruentes con la estructura de hojas de simetría dorsivental y homobaricas, tal como lo indica Crang, Lyons-Sobaski y Wise (2018). Así mismo, Stern (1978) hace una descripción anatómica detallada de las hojas de H. macrophylla donde indica la posición de los estomas, tipo de patrón estomático, estructura, morfología de los tejidos del mesófilo, epidermis foliar, haces vasculares e indica la presencia de rafidios de oxalato de calcio en idioblastos. Todos estos hallazgos son coincidentes con observaciones anatómicas realizadas acá para H. macrophylla. Adicionalmente, Stern (1978) describe la presencia de tricomas e hidátodos que no se apreciaron en esta investigación.

Los engrosamientos cuticulares detectados por la tinción de Safranina-azul de Alcian en las células epidérmicas de las hojas infectadas sugieren una respuesta de reforzamiento de la pared celular con este biopolímero; lo cual ha sido indicado como uno de los mecanismos de respuesta de las plantas ante la penetración de micopatógenos (Marqués, Amorim, Spósito, \& Appezzato-da-Glória, 2016; Ziv, Zhao, Gao, \& Xia, 2018). La presencia de agregados granulares citoplasmáticos de color fucsia, con esta misma tinción, se relaciona con la acumulación de polifenoles; también documentados como mecanismos de defensa de las plantas (Lattanzio, Lattanzio, \& Cardinali, 2006; Aoun, Rioux, Simard, \& Bernier, 2009; Aoun, 2017). La detección indirecta de polifenoles por la tinción con Safranina, ha sido documentada anteriormente (Ruzin, 1999) y lo cual 
se contrastó en esta investigación con la tinción específica para polifenoles con Cloruro férrico. Ordeñana (2002), Lattanzio et al. (2006), Aoun et al. (2009) y Aoun (2017) han indicado, que los polifenoles pueden reforzar las paredes celulares primarias ante la presión y degradación enzimática efectuada por el micopatógeno, impidiendo la penetración de los haustorios a las células y también pueden interferir con la germinación de las esporas.

Se ha señalado, que los compuestos polifenólicos reaccionan con los grupos sulfhidrilos de algunos aminoácidos, lo que conlleva a la inhibición de procesos enzimáticos efectuados por el patógeno (Agrios, 2005; Montes-Belmont, 2009). La acumulación de compuestos polifenolicos en el citoplasma de las células infectadas podrían estar relacionados con la precipitación y coagulación del citoplasma debido a la necrosis generada por la respuesta o reacción de hipersensibilidad $(\mathrm{RH})$ que han sido extensamente documentadas en plantas (Mur, Kenton, Lloyd, Ougham, \& Prats, 2007; Balint-Kurti, 2019).

La RH es considerada como uno de los principales mecanismos de resistencia de las plantas al ataque por micopatógenos y se define como una muerte rápida de las células invadidas, lo cual contribuye a restringir la reproducción y desarrollo de las estructuras del patógeno (Schmelzer, 2002; Li et al., 2009a, b; Sanzón \& Zavaleta, 2011; Balint-Kurti, 2019). La RH ocurre únicamente en combinaciones incompatibles entre plantas hospedantes y patógenos (Agrios, 2005; Balint-Kurti, 2019). La RH origina alteraciones anatómicas que incluyen la contracción, fragmentación y condensación del protoplasto (Sanzón \& Zavaleta, 2011). Estas alteraciones de las células epidérmicas fueron verificadas en esta investigación para el pato-sistema $H$. macropylla-Oidium. Por el contrario, es probable que la necrosis observada en los tejidos parenquimatosos, presentes en el mesófilo de $H$. macrophylla a medida que avanza la infección, está relacionada con el deterioro y muerte de las células epidérmicas, que dejan desprotegidos y expuesto a los tejidos subyacentes, dado que el biotrofo solo afecta a las células epidérmicas.

En las paredes periclinales externas de las células epidérmicas de las hojas infectadas $H$. macrophylla, se observó el depósito de papilas o aposiciones de pared celular que son coincidentes morfológica y estructuralmente a lo registrado en otros pato-sistemas (Ordeñana, 2002; Agrios, 2005; An, Hückelhoven, Kogel, \& Van Bel, 2006; Underwood, 2007; Chowdhury et al., 2014; Houston, Tucker, Chowdhury, Shirley, \& Little, 2016; Kuhn et al, 2016). Li et al. (2009a, 2009b) observaron que estas papilas están reforzadas con calosa en el pato-sistema H. macrophylla-Erysiphe polygoni, lo cual es similar a lo observado en esta investigación y que se corroboró con las tinciones específicas para este polisacárido. La formación de calosa está relacionada con mecanismo de respuesta temprana ante la penetración de fitopatógenos (Voigt, 2014; Houston et al., 2016; Kuhn et al, 2016).

En el caso específico de los hongos, estas papilas, encapsulan los haustorios bloqueando físicamente la penetración en las células epidérmicas (Camarena \& de la Torre, 2007; Voigt, 2014; Chowdhury et al., 2014; Kuhn et al, 2016). Así mismo, se ha comprobado que inhiben la difusión de sustancias tóxicas secretadas en el momento de la infección (Underwood, 2007; Voigt, 2014; Kuhn et al., 2016), lo cual suprimen la nutrición del patógeno y repara el daño celular (Agrios, 2005). Adicionalmente, se ha establecido la acumulación de varios metabolitos secundarios como polifenoles, lignina y especies reactivas de oxígeno (ROS) en las papilas presentes en varios pato-sistemas (Bhuiyan, Selvaraj, Wei, \& King, 2009; Clay, Adio, Denoux, Jander, \& Ausubel 2009; Voigt, 2014; Malinovsky, Fangel, \& Willats, 2014; Aoun, 2017; Bacete, Mélida, Miedes, \& Molina, 2018). En esta investigación no se detectó la acumulación de lignina en las papilas o en las paredes de las células epidérmicas como mecanismos de respuesta de la planta al patógeno, indicado por estos mismos autores. Tampoco se evidencio la presencia de polifenoles relacionados a las papilas, es de aclarar que no 
se efectuaron pruebas para ROS, pero la necrosis observada también podría estar asociada a estos compuestos.

Chowdhury et al. (2014) determinó la presencia de pectinas asociadas a las papilas, además de la calosa, en hojas de cebada, afectadas por Blumeria graminis f. sp. Hordei, resaltando su papel en el reforzamiento de la pared celular. Estas observaciones son similares a lo registrado en esta investigación para H. macrophylla. La presencia de engrosamientos de pectina en las paredes primarias de las células epidérmicas infectadas con Oidiosis en H. macrophylla aportarían reforzamiento a las paredes celulares para prevenir la entrada del patógeno. Esta situación ha sido documentada por Vogel, Raab, Somerville y Somerville (2004) y Engelsdorf et al. (2017) en sus investigaciones con mutantes de Arabidopsis Heynh. in Holl \& Heynh en relación a la resistencia contra algunas especies de Erysiphe y Colletotrichum higginsianum Sacc. respectivamente.

Varios autores han documentado la activación de rutas metabólicas relacionadas con la síntesis de moléculas de naturaleza lipídica en células vegetales afectadas por patógenos, principalmente para hongos y virus e indican la importancia de estos en las rutas metabólicas asociadas a mecanismos de defensa de las plantas en especial con la biosíntesis de oxilipinas, jamonatos, glicerolípidos y ácidos grasos (Reina \& Yephremov, 2009; Marqués, Kitajima, Freitas-Astúa, \& Appezzato-da-Glória, 2010; Canonne, Froidure-Nicolas, \& Rivas, 2011; Walley, Kliebenstein, Bostock, \& Dehesh 2013; Zhang \& Xiao, 2015; Laureano et al., 2018). La acumulación de lípidos en las células epidérmicas del pato-sistema $H$. macrophyllaOidiosis es coincidente con estas observaciones. Dado que el patógeno causante de la Oidiosis analizado en esta investigación es un biotrofo obligado de las células epidérmicas, estos mecanismos de defensa no explicarían los agregados lipídicos observados en las células parenquimatosas del mesófilo, que probablemente estarían relacionados con el deterioro y desorganización de los sistemas de membrana de estas células.

A pesar de que el fluorocromo Uvitex 2B presentó reacción cruzada con los componentes de la pared primaria de las células epidérmicas y del mesófilo de $H$. macrophylla, correspondiente a la longitud de onda de emisión del azul oscuro-violeta; la emisión de la interacción con la quitina se dio en una longitud del azul claro brillante, permitiendo diferenciar sin dificultad las células del patógeno de los tejidos de la planta. Lo anterior indica que este fluorocromo es ideal para el análisis de las interacciones histológicas en este tipo de pato-sistemas, tal y como se ha indicado para la interacción entre plantas y royas (Sørensen et al., 2012; Dugyala et al., 2015)

Finalmente, la conclusión amplia de este trabajo permite establecer que las células epidérmicas de las hojas de H. macrophylla, despliegan una serie de mecanismos de defensa ante el ataque del agente causante de la Oidiosis. Estos mecanismos, incluyen el reforzamiento de las paredes celulares con la acumulación de pectinas, cutina y calosa. Además, la secreción de metabolitos secundarios, principalmente polifenoles. Es probable que la muerte de las células epidérmicas tenga relación con la RH que han sido documentada previamente para $H$. macrophylla por el ataque de micopatógenos del género Erysiphe. Todos estos mecanismos estas destinados a contrarrestan la penetración, propagación e inhiben el desarrollo del patógeno.

Declaración de ética: los autores declaran que todos están de acuerdo con esta publicación y que han hecho aportes que justifican su autoría; que no hay conflicto de interés de ningún tipo; y que han cumplido con todos los requisitos y procedimientos éticos y legales pertinentes. Todas las fuentes de financiamiento se detallan plena y claramente en la sección de agradecimientos. El respectivo documento legal firmado se encuentra en los archivos de la revista. 


\section{AGRADECIMIENTOS}

Los autores agradecen a las siguientes instituciones y personas: al Laboratorio de Investigación e Innovación en Biotecnología Agroambiental, Universidad de Santander (LIIBAAM-UDES), al Laboratorio de Botánica de la Universidad de Antioquia (UDEA), al Laboratorio de Biotecnología de la Universidad de Antioquia (UDEA), a la Corporación Colombiana de Investigación Agropecuaria (AGROSAVIA) y a los revisores anónimos, por las críticas y valiosas sugerencias al documento final.

\section{RESUMEN}

Introducción: Los estudios sobre las alteraciones morfo-anatómicas e histoquímicas ocasionadas por la Oidiosis o ceniza en hojas de Hydrangea macrophylla son escasos en la literatura científica. Objetivos: describir y analizar aspectos anatómicos e histopatológicos de este patosistema. Métodos: se tomaron más de 90 hojas de $H$. macrophylla sanas e infectadas por Oidiosis que se recolectaron en el vivero El Jardín del Edén, Rionegro, AntioquiaColombia. Para la identificación del micopatógeno, las secciones obtenidas se tiñeron con azul de Lactofenol y se consultaron claves taxonómicas especializadas. Fragmentos transversales de $1 \mathrm{~cm}$ de grosor que se fijaron en una mezcla de formol, alcohol y ácido acético. Posteriormente, se deshidrataron en una serie de etanol, se aclararon en Xilol y finalmente, se incluyeron en Paraplast plus ${ }^{\circledR}$ para obtener secciones de $5 \mu \mathrm{m}$. Se utilizó la reacción del ácido peryódico de Schiff (PAS) para detectar polipolisacáridos, rojo de Rutenio para pectinas, Ponseau S y Lacmoid para calosa, Cloruro férrico para polifenoles, negro de Sudan para lípidos y Uvitex 2B-Hematoxilina para quitina. Las secciones se observaron mediante un microscopio fotónico Nikon 80 i eclipse ${ }^{\circledR}$ y con epifluorescencia empleando filtro UV-2A. Para la observación con microscopía electrónica de barrido, hojas sanas e infectadas fueron fijadas y deshidratadas en metanol al $100 \%$, desecadas al punto crítico y recubiertas con oro. Resultados: las hojas de $H$. macropylla son dorsiventrales, homobáricas, con epidermis adaxial y abaxial de un solo estrato celular. El parénquima de empalizada está constituido por un estrato de células cortas. En tanto que el parénquima esponjoso forma entre 6-7 estratos celulares. Todos los haces vasculares en la lámina foliar son colaterales cerrados. Se aprecian abundantes idioblastos en el mesófilo con rafidios; el almidón es el principal carbohidrato. Las hojas son hipostomáticas de patrones paracíticos, estos son superficiales y con amplias cavidades subestomáticas. Los datos morfológicos apreciados en el micopatógeno, están relacionados con el género Erysiphe. Las células epidérmicas afectadas por el patógeno se aprecian con pared engrosada, citoplasma granular y papilas o aposiciones de la pared celular presentes en las paredes periclinales externas. Con el deterioro de la epidermis, los tejidos subyacentes se afectan y se aprecian necróticos. Los análisis histoquímicos demuestran que las plantas infectadas engrosan y refuerzan sus paredes celulares epidérmicas con materiales de pared primaria, principalmente, cutina, pectinas y calosa. La presencia de aglomerados de color oscuro teñidos con el Sudan negro, en el citoplasma de las células epidérmicas, podrían relacionarse con mecanismos de defensa de la planta y los observados en las células del mesófilo con la desorganización de los sistemas de membrana. Los polifenoles se acumulan en el citoplasma de las células epidérmicas infectadas. El material fúngico presente en los tejidos epidérmicos fue diferenciado claramente al ser teñido con el fluorocromo para quitina. Conclusiones: El agente causal de la Oidiosis o ceniza en H. macrophylla está relacionado con especies del género Erysiphe. Se aprecia necrosis de las células epidérmicas en respuesta al patógeno, que podría estar relacionado con respuestas de hipersensibilidad.

Palabras clave: biotrofos; histopatología de plantas; histoquímica; hoja; Hydrangeaceae; oidiosis; papilas.

\section{REFERENCIAS}

Agronegocios. (2019). Cultivo de Hortensias, un negocio con gran potencial en el Oriente Antioqueño. Obtenido de Agronegocios: www.agronegocios.co/ agricultura/cultivo-de-hortensias-un-negocio-congran-potencial-en-el-oriente-antioqueno-2821240

Ministerio de Agricultura y Desarrollo Rural de Colombia. (2018). Estadísticas Agronet (Base de datos). Recuperado de http://www.agronet.gov.co/estadistica/Paginas/home.aspx?cod=1

Agrios, G.N. (2005). Plant pathology. San Diego, USA: Academic Press Inc.

Ale-Agha, N., Boyle, H., Braun, U., Butin, H., Jage, H., Kummer, V., \& Shin, H.D. (2013). Taxonomy, host range and distribution of some powdery mildew fungi (Erysiphales). Schlechtendalia, 17, 39-54.

An, Q., Hückelhoven, R., Kogel, K.H., \& Van Bel, A.J. (2006). Multivesicular bodies participate in a cell wall-associated defence response in barley leaves attacked by the pathogenic powdery mildew fungus. Cellular Microbiology, 8(6), 1009-1019.

APG IV (2016). An update of the Angiosperm Phylogeny Group classification for the orders and families of flowering plants. Botanical Journal of the Linnean Society, 181, 1-20. 
Arafa, A.M.S., Nower, A.A., Helme, S.S., \& Abd-Elaty, H.A. (2017). Large scales of Hydrangea macrophylla using tissue culture technique. International Journal of Current Microbiology and Applied Sciences, 6(5), 776-778.

Aoun, M. (2017). Host defense mechanisms during fungal pathogenesis and how these are overcome in susceptible plants: A review. International Journal of Botany, $13,82-102$

Aoun, M., Rioux, D., Simard, M., \& Bernier, L. (2009). Fungal colonization and host defense reactions in Ulmus americana callus cultures inoculated with Ophiostoma novo-ulmi. Phytopathology, 99, 642-650.

Balint-Kurti, P. (2019). The plant hypersensitive response: concepts, control and consequences. Molecular Plant Pathology, 20(8), 1163-1178.

Basterrechea, H.G. (2005). Algunos aspectos sobre las principales especies de fitonemátodos asociadas a los cultivos de plantas ornamentales. Fitosanidad, 9(2), 49-57.

Bacete, L., Mélida, H., Miedes, E., \& Molina, A. (2018) Plant cell wall-mediated immunity: cell wall changes trigger disease resistance responses. The Plant Journal, 93(4), 614-636.

Braun U, Cook RTA. 2012. Taxonomic manual of the Erysiphales (powdery mildews). The Netherlands: CBS-KNAW Fungal Biodiversity Centre.

Bhuiyan, N.H., Selvaraj, G., Wei, Y., \& King, J. (2009). Role of lignification in plant defense. Plant Signaling \& Behavior, 4(2), 158-159.

Calderón, M.D.P.S. (2014). Análisis de eficiencia técnica y estudio de casos en los cultivos de flores de la Sabana de Bogotá. Pensamiento \& Gestión, 36, 291-326.

Camarena, G.G., \& de la Torre, A.R. (2007). Resistencia sistémica adquirida en plantas: estado actual. Revista Chapingo. Serie Ciencias Forestales y del Ambiente, 13(2), 157-162.

Canonne, J., Froidure-Nicolas, S., \& Rivas, S. (2011) Phospholipases in action during plant defense signaling. Plant Signaling \& Behavior, 6(1), 13-18.

Cerbah, M., Mortreau, E., Brown, S., Siljak-Yakovlev, S., Bertrand, H., \& Lambert, C. (2001). Genome size variation and species relationships in the genus Hydrangea. Theoretical and Applied Genetics, 103(1), 45-51.

Chowdhury, J., Henderson, M., Schweizer, P., Burton, R.A., Fincher, G.B., \& Little, A. (2014). Differential accumulation of callose, arabinoxylan and cellulose in non-penetrated versus penetrated papillae on leaves of barley infected with Blumeria graminis f. sp. hordei. New Phytologist, 204(3), 650-660.
Clay, N.K., Adio, A.M., Denoux, C., Jander, G., \& Ausubel, F.M. (2009). Glucosinolate metabolites required for an Arabidopsis innate immune response. Science, 323(5910), 95-101.

Codarin, S., Galopin, G., \& Chasseriaux, G. (2006). Effect of air humidity on the growth and morphology of Hydrangea macrophylla L. Scientia Horticulturae, 108(3), 303-309.

Crang, R., Lyons-Sobaski, S., \& Wise, R. (2018). Plant Anatomy: A Concept-Based Approach to the Structure of Seed Plants. Cham, Switzerlan: Springer.

Dean, R.A. (1997). Signal pathways and appressorium morphogenesis. Annual Review of Phytopathology, $35(1), 211-234$.

Demarco, D. (2017). Histochemical analysis of plant secretory structures. In C. Pellicciari \& M. Biggiogera (Eds.), Histochemistry of single molecules methods and protocols (pp. 313-330). New York, USA: Humana Press.

Dirr, M.A. (2004). Hydrangeas for American Gardens. Portland: Timber Press.

Dória, K.M.A.B.V., Nozaki, D.N., Pavan, M.A., Yuki, V.A., \& Sakate, R.K. (2011). Identification and characterization of a Hydrangea ringspot virus isolate infecting hydrangea in São Paulo State. Summa Phytopathologica, 37(2), 125-128.

Dugyala, S., Borowicz, P., \& Acevedo, M. (2015). Rapid protocol for visualization of rust fungi structures using fluorochrome Uvitex 2B. Plant Methods, $11(1), 54$

Engelsdorf, T., Will, C., Hofmann, J., Schmitt, C., Merritt, B.B., Rieger, L., Frenger, S.M., Marschal, A., Franke, B.R., Pattathil, S., \& Voll, L.M. (2017). Cell wall composition and penetration resistance against the fungal pathogen Colletotrichum higginsianum are affected by impaired starch turnover in Arabidopsis mutants. Journal of Experimental Botany, 68(3), 701-713.

Fontseré, A.C., \& Pahí, L.R. (1984). El cultivo de la hortensia (II parte). Plagas y enfermedades. Horticultura: Revista de industria, distribución y socioeconomía hortícola: frutas, hortalizas, flores, plantas, árboles ornamentales y viveros, 17, 47-54.

Freire, F.C.O., \& Mosca, J.L. (2009). Patógenos associados a doenças de plantas ornamentais no Estado do Ceará. Revista Brasileira de Horticultura Ornamental, 15(1), 83-89.

French, N., John, M.E., \& Williams, J.J.W. (1971). Observations on the biology and control of stem Eelworm (Ditylenchus dipsaci (Kühn) Filipjev) on Hydrangea (Hydrangea macrophylla Ser.). Plant Pathology, 20(4), 177-183. 
Gilman, E. (1999). Hydrangea macrophylla. Florida, USA: Institute of Food and Agricultural Sciences.

Hagan, A.K., Olive, J.W., Stephenson, J., \& Rivas-Davila, M.E. (2004). Impact of application rate and interval on the control of powdery mildew and Cercospora leaf spot on bigleaf Hydrangea with azoxystrobin. Journal of Environmental Horticulture, 22(2), 58-62.

Halcomb, M., \& Reed, S. (2010). Hydrangea production. USA: University of Tennessee.

Hempel, P., Hohe, A., \& Tränkner, C. (2018). Molecular reconstruction of an old pedigree of diploid and triploid Hydrangea macrophylla genotypes. Frontiers in Plant Science, 9, 1-13.

Hufford, L. (2004). Hydrangeaceae. In K. Kubitzki (Ed.), Flowering Plants. Dicotyledons: Celastrales, Oxalidales, Rosales, Cornales, Ericales (Vol. 6, pp. 202-215). Heidelberg, Germany: Springer Science \& Business Media.

Houston, K., Tucker, M.R., Chowdhury, J., Shirley, N., \& Little, A. (2016). The plant cell wall: a complex and dynamic structure as revealed by the responses of genes under stress conditions. Frontiers in Plant Science, 7, 984, 1-18.

Instituto colombiano Agropecuario. (2018a). El ICA supervisa la calidad fitosanitaria de cerca 600 millones de tallos de flores enviados a los Estados Unidos para la fiesta de San Valentín. Recuperado de http://www. agronet.gov.co/Noticias/Paginas/httpswww-ica-govcoNoticiasica-flores-colombianas-sanvalentin-aspx. aspx

Instituto colombiano Agropecuario. (2018b). El ICA apoya el florecimiento del sector ornamental de Antioquia. Recuperado de https://www.ica.gov.co/noticias/ ica-apoya-exportacion-ornamental-antioquia

Kuhn, H., Kwaaitaal, M., Kusch, S., Acevedo, Garcia, J., Wu, H., \& Panstruga, R. (2016). Biotrophy at its best: novel findings and unsolved mysteries of the Arabidopsis-powdery mildew pathosystem. The Arabidopsis Book/American Society of Plant Biologists, 14, 1-24.

Laureano, G., Figueiredo, J., Cavaco, A.R., Duarte, B., Caçador, I., Malhó, R., Silva, S.M., Matos, R.A., \& Figueiredo, A. (2018). The interplay between membrane lipids and phospholipase A family members in grapevine resistance against Plasmopara viticola. Scientific Reports, 8, 1-15.

Lattanzio, V., Lattanzio, M.T.V., \& Cardinali, A. (2006). Role of phenolics in the resistance mechanisms of plants against fungal pathogens and insects. In F. Imperato (Ed.), Phytochemistry: advances in research (pp. 23-67). Trivandrum, India: Research Signpost.

Li, Y., Windham, M.T., Trigiano, R.N., Reed, S.M., Spiers, J.M., \& Rinehart, T.A. (2009a). Bright-field and fluorescence microscopic study of development of Erysiphe polygoni in susceptible and resistant bigleaf Hydrangea. Plant Disease, 93(2), 130-134.

Li, Y., Windman, M., Trigiano, R., Reed, S., Rinehart, T. \& Spiers, J. (2009b). Assessment of resistance components of bigleaf hydrangeas (Hydrangea macrophylla) to Erysiphe polygoni in vitro. Canadian Journal of Plant Pathology, 31(3), 348-355.

Li, Y., Mmbaga, M.T., Zhou, B., Joshua, J., Rotich, E., \& Parikh, L. (2018). Diseases of Hydrangea. In R.J. McGovern \& W.H. Elmer (Eds.), Handbook of florists' crops diseases (pp. 987-1006). Cham, Switzerland: Springer International Publishing.

Malinovsky, F.G., Fangel, J.U., \& Willats, W.G. (2014). The role of the cell wall in plant immunity. Frontiers in Plant Science, 5, 178, 1-12.

Marqués, J.P.R., Amorim, L., Spósito, M.B., \& Appezzatoda-Glória, B. (2016). Ultrastructural changes in the epidermis of petals of the sweet orange infected by Colletotrichum acutatum. Protoplasma, 253(5), 1233-1242.

Marqués, J.P., Kitajima, E.W., Freitas-Astúa, J., \& Appezzato-da-Glória, B. (2010). Comparative morphoanatomical studies of the lesions caused by Citrus leprosis virus on sweet orange. Anais da Academia Brasileira de Ciências, 82(2), 501-511.

MinCIT-Ministerio de Comercio, Industria y Turismos, Colombia. (2019). Cerca de 35 mil toneladas de flores colombianas fueron exportadas para cubrir la demanda de San Valentín 2019. Recuperado de www.mincit.gov.co/prensa/noticias/comercio/ exportacion-flores-san-valentin-2019

Mmbaga, M.T., Kim, M.S., Mackasmiel, L., \& Li, Y. (2012). Evaluation of Hydrangea macrophylla for resistance to leaf-spot diseases. Journal of Phytopathology, 160(2), 88-97.

Montes-Belmont, R. (2009). Diversidad de compuestos químicos producidos por las plantas contra hongos fitopatógenos. Revista Mexicana de Micología, 29, 73-82.

Moreno, F.O.L., \& Serna, C.F.J. (2006). Biology of Peridroma saucia (Lepidoptera: Noctuidae: Noctuinae) on flowers of the commercial hybrid of Alstroemeria spp. Revista Facultad Nacional de Agronomía, Medellin, 59(2), 3435-3448.

Mur, L.A., Kenton, P., Lloyd, A.J., Ougham, H., \& Prats, E. (2007). The hypersensitive response; the centenary is upon us but how much do we know? Journal of Experimental Botany, 59(3), 501-520.

Ordeñana, K.M. (2002). Mecanismos de defensa en las interacciones planta-patógeno. Revista Manejo Integrado de Plagas. Costa Rica, 63, 22-32. 
Park, M.J., Cho, S.E., Park, J.H., Lee, S.K., \& Shin, H.D. (2012). First report of powdery mildew caused by Oidium hortensiae on mophead Hydrangea in Korea. Plant Disease, 96(7), 1072-1072.

Peterson, R.L., Peterson, C.A., \& Melville, L.H. (2008). Teaching plant anatomy through creative laboratory exercises. Ottawa, Canada: NRC Research Press.

Quirós, M.L. (2012). La Floricultura en Colombia en el marco de la globalización: Aproximaciones hacia un análisis micro y macroeconómico. Revista Universidad EAFIT, 37(122), 59-68.

Qiu, P.L., Braun, U., Li, Y., \& Liu, S.Y. (2019). Erysiphedeutziicola sp. nov. (Erysiphaceae, Ascomycota), a powdery mildew species found on Deutziaparviflora (Hydrangeaceae) with unusual appendages. MycoKeys, 51, 97-106.

Ramírez, L.N.M. (2014). Floricultura colombiana en contexto: experiencias y oportunidades en Asia pacífico. Revista Digital Mundo Asia Pacífico, 3(5), 52-79.

Ramming, D.W., Hinrichs, H.A., \& Richardson, P.E. (1973). Sequential staining of callose by aniline blue and lacmoid for fluorescence and regular microscopy on a durable preparation of the same specimen. Stain Technology, 48(3), 133-134.

Reed, S.M., \& Rinehart, T.A. (2007). Simple sequence repeat marker analysis of genetic relationships within Hydrangea macrophylla. Journal of the American Society for Horticultural Science, 132(3), 341-351.

Reina, P.J.J., \& Yephremov, A. (2009). Surface lipids and plant defenses. Plant Physiology and Biochemistry, 47(6), 540-549.

Ruzin, S.E. (1999). Plant microtechnique and microscopy. New York, USA: Oxford University.

Ryder, L.S., \& Talbot, N.J. (2015). Regulation of appressorium development in pathogenic fungi. Current Opinion in Plant Biology, 26, 8-13.

Sandoval, E. (2005). Técnicas aplicadas al estudio de la anatomía vegetal. México D.F: UNAM.

Sanzón, G.D., \& Zavaleta, M.E. (2011). Respuesta de hipersensibilidad, una muerte celular programada para defenderse del ataque por fitopatógenos. Revista Mexicana de Fitopatología, 29(2), 154-164.

Schmelzer, E. (2002). Cell polarization, a crucial process in fungal defence. Trends in Plant Science, 7(9), $411-415$.

Schmidt, A., \& Scholler, M. (2011). Studies in Erysiphales anamorphs (4): species on Hydrangeaceae and Papaveraceae. Mycotaxon, 115(1), 287-301.

Seo, J.S., Lee, T.H., Lee, S.M., Lee, S.E., Seong, N.S., \& Kim, J.Y. (2009). Inhibitory effects of methanolic extracts of medicinal plants on nitric oxide production in activated macrophage RAW 264.7 cells. Korean Journal of Medicinal Crop Science, 17(3), 173-178.

Simpson, M.G. (2010). Plant systematics. San Diego, USA: Academic press.

Sinclair, W.A., \& Lyon, H.H. (2005) Diseases of trees and shrubs (Second Ed.). Ithaca, USA: Cornell University Press.

Sørensen, C.K., Justesen, A.F., \& Hovmøller, M.S. (2012). 3-D imaging of temporal and spatial development of Puccinia striiformis haustoria in wheat. Mycologia, 104(6), 1381-1389.

Soukup, A. (2014). Selected simple methods of plant cell wall histochemistry and staining for light microscopy. En V. Žárský, \& F. Cvrčková (Eds.), Plant cell morphogenesis: methods and protocols, methods in molecular biology (pp. 25-40). New York, USA: Humana Press.

Stern, W.L. (1978). Comparative anatomy and systematics of woody Saxifragaceae. Hydrangea. Botanical Journal of the Linnean Society, 76(2), 83-113.

Talbot, M.J., \& White, R.G. (2013). Methanol fixation of plant tissue for scanning electron microscopy improves preservation of tissue morphology and dimensions. Plant Methods, 9(1), 36.

Tang, J., Harper, S.J., Wei, T., \& Clover, G.R. (2010). Characterization of Hydrangea chlorotic mottle virus, a new member of the genus Carlavirus. Archives of Virology, 155(1), 7-12.

Ulryghová, M., Petrü, E., \& Pazourková, Z. (1976). Permanent staining of callose in plant material by Ponceau S. Stain Technology, 51(5), 272-275.

Underwood, W. (2007). The plant cell wall: a dynamic barrier against pathogen invasion. Current Challenges in Plant Cell Walls, 3(85), 67.

Vogel, J.P., Raab, T.K., Somerville, C.R., \& Somerville, S.C. (2004). Mutations in PMR5 result in powdery mildew resistance and altered cell wall composition. The Plant Journal, 40(6), 968-978.

Voigt, C.A. (2014). Callose-mediated resistance to pathogenic intruders in plant defense-related papillae. Frontiers in Plant Science, 5, 1-6.

Walley, J.W., Kliebenstein, D.J., Bostock, R.M., \& Dehesh, K. (2013). Fatty acids and early detection of pathogens. Current Opinion in Plant Biology, 16(4), 520-526.

Windham, M.T., Reed, S.M., Mmbaga, M.T., Windham, A.S., Li, Y., \& Rinehart, T.A. (2011). Evaluation of powdery mildew resistance in Hydrangea 
macrophylla. Journal of Environmental Horticulture, 29(2), 60-64.

Yashaswini, S., Hegde, R.V., \& Venugopal, C.K. (2011). Health and nutrition from ornamentals. International Journal of Research in Ayurveda \& Pharmacy, 2(2), 375-382.

Zabka, V., Stangl, M., Bringmann, G., Vogg, G., Riederer, M., \& Hildebrandt, U. (2008). Host surface properties affect prepenetration processes in the barley powdery mildew fungus. New Phytologist, 177(1), 251-263.

Zhang, Q., \& Xiao, S. (2015). Lipids in salicylic acidmediated defense in plants: focusing on the roles of phosphatidic acid and phosphatidylinositol 4-phosphate. Frontiers in Plant Science, 6, 387, 1-7.

Ziv, C., Zhao, Z., Gao, Y.G., \& Xia, Y. (2018). Multifunctional roles of plant cuticle during plant-pathogen interactions. Frontiers in Plant Science, 9, 2-8. 